\title{
TUG OF WAR: EVALUATIVE VERSUS FACILITATIVE MEDIATOR
}

\author{
By Diksha Munjal*
}

\section{Introduction}

Mediation can be defined as a process where a neutral third party seeks to facilitate communication between the disputing parties to help them arrive at an amicable solution of their disputes culminating in a win-win situation for the parties. Though '.. there is no single limiting definition of mediation, in part because mediators function in accordance with different philosophies and in statistically different ways', 1 the most commonly accepted definitions of mediation ${ }^{2}$ incorporate two essential elements: '(1) third-party facilitation of dispute settlement, and (2) lack of third-party power to determine

Research Associate, National Law University Delhi.

MS Levin 'The propriety of evaluative mediation: concerns about the nature and quality of an evaluative opinion' (2001) 16 Ohio State Journal on Dispute Resolution 267.

$2 \mathrm{Eg}$ on certain aspects of mediation in civil and commercial matters. Council Directive (EC) 2008/52 (2008) OJ L136/3 art 3(a) http://www.eur-lex.europa.eu/ LexUriServ/LexUriServ.do?uri=OJ:L:2008:136:0003:0008:EN:PDF (accessed on 11 November 2011) (hereinafter 'EC Directive'). It defines mediation to mean: a structured process, however named or referred to, whereby two or more parties to a dispute attempt by themselves, on a voluntary basis, to reach an agreement on the settlement of their dispute with the assistance of a mediator. This process may be initiated by the parties or suggested or ordered by a court or prescribed by the law of a Member State. The Law Society 'Civil and commercial mediation accreditation scheme: criteria and guidance notes, annex- $B$ ' in The Law Society code of practice for civil and commercial mediation (July 2009) sec 1 http:// www.lawsociety.org.uk/new/documents/accreditation/ccmas_guidance.pdf (accessed on 11 November 2011) (hereinafter 'Annex-B CPCCM'). It defines mediation as: a process in which two or more parties in dispute whether or not they are legally represented and at any time, whether or not there are or have been legal proceedings agree to the appointment of a neutral third party (the mediator) who is impartial, who has no authority to make any decisions with regard to their issues, which may relate to all or any part of a dispute of a civil or commercial nature, but who helps them reach their own decisions by negotiation without adjudication. The Law Society 'Family Mediation Accreditation Scheme: Criteria and guidance notes, Annex-A 'in the The Law Society code of practice for family mediation (July 2009) sec 1 http://www.lawsociety.org.uk/new/ documents/accreditation/family-mediation-accreditation-scheme-guidance.pdf (accessed on 13 November 2011) (hereinafter 'Annex-A CPFM'). Defines 'family mediation' on similar lines. College of Mediators Code of practice for mediators (2008) para 1.2 http://www.collegeofmediators.com/index.php?option=com_rok downloads\&view=file\&ltemid=18\&id=5: code-of-practice (accessed on 13 November 2011) (hereinafter 'CMCPM'). It defines mediation as: a process in which an impartial third party assists those involved in a conflict to communicate better with one another and reach their own agreed and informed decisions concerning some, or all, of the issues in the dispute. RAB Bush 'The dilemmas of mediation practice: A study of ethical dilemmas and policy implications' (1994) 
the resolution of the dispute. ${ }^{3}$ The central focus of mediation is based on the principle of parties' self-determination. To further this basic principle, the role of a mediator must be well defined.

Looking at mediation from a historical perspective, mediation was confined to the facilitative role of a neutral third party. Gradually, however, there came a sharp divide amongst the existing mediators as regards the scope of intervention by a mediator in the mediation proceedings. At one end of the broad spectrum of a mediator's role, lies his or her active role as an evaluator and at the other, that as a facilitator of communication between the parties. These two positions are, however, in contrast with each other and hence, the debate as to the most suitable role of a mediator's intervention in the process. $^{4}$

In part II(a) of the present paper I attempt to portray the distinction between mediators and decision-makers. Because of the emergence of evaluative forms in mediation. In part II(b) I sketch the differences between the approaches taken by the facilitative and the evaluative mediators. In part III I try to indicate the dangers posed when mediators strive to put on the evaluative cloak and finally and in part IV I sum up the paper with an appropriate conclusion.

\section{Drawing the lines}

\subsection{Distinguishing mediators from decision-makers}

Mediation is unique in the sense that when compared to other forms of dispute resolution mechanisms, it is resorted to as an 'alternative'

Journal of Dispute Resolution 1, 2-3. Mediation is commonly described as a consensual process in which a neutral third party, without any power to impose a resolution, works with the disputing parties to help them reach a mutually acceptable resolution of some or all of the issues in dispute.

3 DT Weckstein 'In praise of party empowerment - and of mediator activism' (1997) 33 Willamette Law Review 501,508.

4 LP Love 'Top ten reasons why mediators should not evaluate' (1997) 24 Florida State University Law Review 937; JJ Alfini 'Evaluative versus facilitative mediation: a discussion’ (1997) 24 Florida State University Law Review 919; RB Moberly 'Mediator gag rules: is it ethical for mediators to evaluate or advise?' (1997) 28 South Texas Law Review 669; JB Stulberg 'Facilitative versus evaluative mediator orientations: piercing the grid lock' (1997) 24 Florida State University Law Review 985. Levin (n 1 above) 267; LL Riskin “"Understanding mediators” orientations, strategies, and techniques: a grid for the perplexed' (1996) 1 Harvard Negotiation Law Review 7; JH Stark 'The ethics of mediation evaluation: some troublesome questions and tentative proposals, from an evaluative lawyer mediator' (1997) 38 South Texas Law Review 769; JW Stempel 'Beyond formalism and false dichotomies: the need for institutionalising a flexible concept of the mediator's role' (1997) 24 Florida State University Law Review 949; RP Schuwerk 'Reflections on ethics and mediation' (1997) 38 South Texas Law Review 757. 
to the usual adversarial method of dispute resolution ${ }^{5}$ and is intended to be a practice free from such a feature.

'Evaluating, assessing, and deciding for others is radically different than helping others evaluate, assess, and decide for themselves. ${ }^{6}$ Evaluators include judges, arbitrators, neutral experts, and advisors. ${ }^{7}$ A comparison of arbitration and mediation show that though an arbitrator and a mediator are similar in terms of being a neutral third-party chosen by the parties themselves, they have different functional roles. The role of an arbitrator is to go through the pleadings, examine the evidence, hear both the parties, look into the merits of the case, and thereafter make an award. The arbitrator cannot have private sessions with the parties to the dispute. The disputants expressly ask the evaluator ie the arbitrator to preside over their case or resolve the conflict. ${ }^{8}$ In contrast, the role of the mediator is to assist the parties to make them understand each other's points of view by facilitating better communication between them, and thereby empowering them to reach a harmonious, consensual solution. To achieve this in the process the mediator also goes through private sessions and maintains confidentiality. The task of the mediator does not go beyond the above-mentioned role. On the conclusion of mediation, the mediator either helps the parties to draw up a simple statement outlining the parties' agreement or in case no settlement is arrived at by the parties, the mediator is not supposed to give any reasons for failure. He only reports that the process of mediation is complete but no settlement is arrived at.

The EC Directive, though not expressly, hints at this distinction between mediation and processes of adjudicatory nature. This is reflected in its Preamble paragraph 11 which provides that the Directive should not be applicable:

to processes of an adjudicatory nature such as certain judicial conciliation schemes, consumer complaint schemes, arbitration and expert determination or to processes administered by persons or bodies issuing a formal recommendation, whether or not it be legally binding as to the resolution of the dispute.

By incorporating such a provision, the Directive recognises the two analytically different processes and seeks to put them on two different platforms. The essence of mediation lies in the fact that 'decision-making is the province of the parties' ${ }^{9}$ If this core feature is eroded, mediation ceases to perform its true function.

5 This includes litigation in courts, arbitration, and neutral-evaluation by a neutral third-party where disputing parties acting in an adversarial manner try to put their best case forward to incline the evaluator towards their respective sides.

Love (n 4 above) 938.

Love (n 4 above) 938.

Love (n 4 above) 938.

LP Love 'Mediation: the romantic days continue' (1997) 38 South Texas Law Review 735,738. 


\subsection{Distinguishing a facilitative from evaluative mediator}

Riskin in his formulation of the mediators' orientations grid states that the role of mediator can be either facilitative or evaluative. There are certain analytical differences ${ }^{10}$ between the two which may now be dealt with. ${ }^{11}$

The fundamental role of a mediator is to act as a facilitator of communication between the parties. A facilitative mediator helps the parties understand their underlying interests, emphasises the need for the parties to educate themselves and each other more than the mediator, helps them develop and propose broad, interest based options for settlement, and to evaluate proposals. ${ }^{12}$ An evaluative mediator, on the other hand gives advice, assesses the strengths and weaknesses of each side's case, predicts outcomes of court or other processes, proposes fairly directive agreements and urges or pushes the parties to settle or to accept a particular settlement proposal or range. ${ }^{13}$ Therefore, the decision-making process passes from the hands of the parties into those of the evaluator.

'Widespread as these activities have become, they are inconsistent with the role of a mediator, 14 and in fact, change the whole perspective of mediation. As both the so-called 'categories' of mediation require their own unique competencies, skills and techniques, they are at two very different positions from one other, and can never be put or compared on the same plane. ${ }^{15}$ Whenever any evaluation is done by the mediator three elements get intricately compromised, namely, principle of self-determination, fairness and the mediator's neutrality and impartiality.

\section{Dangers posed when boundaries are crossed- over}

Parties' participation in the process is a key feature of mediation and is implicit in the parties' right to self determination. If the mediator takes over the process and the decision-making task, not only does it

10 S Roberts \& M Palmer Dispute processes: ADR and the primary forms of decision making (2005) 155 (Roberts \& Palmer observed that "two analytically distinct forms of intervention, with quite different processual shapes, become concealed beneath the conventional label of mediation.').

11 Riskin (n 4 above) 7.

12 Riskin (n 4 above) 32-34. Riskin describing the techniques put to use by facilitative mediators.

13 Riskin ( 4 above) 27, 28. Riskin describing the techniques put to use by evaluative mediators.

14 KK Kovach \& LP Love 'Evaluative mediation is an oxymoron' (1996) 14

15 Alternatives To The High Cost of Litigation 31.

15 Love (n 4 above) 939. Kovach \& Love (n 14 above) 32. 
endanger the parties' right but also changes the very nature of mediation.

\subsection{Change of nature of mediation}

Mediation should be a 'pure play'16 - '[i]t should connote facilitation. 17 If the evaluative ink taints mediation, the process will be affected and it will assume adversarial hues. Evaluative mediators hinder prospects of an environment conducive for settlement. The moment mediation is portrayed as a process wherein the mediator has the power to provide evaluation of the case, the parties get 'in a competitive mind-set seeking to capture the evaluator's favour and win the case. ${ }^{\prime 18}$ They compete with each other to put before the mediator their best case and use different tactics, just as in litigation, to get the attention of the mediator to decide in their favour. ${ }^{19}$ The disputants view the mediator equivalent to a person with adjudicatory functions and 'rely on this outside authority like a judge to decide the case for them' ${ }^{20}$ The foundation of mediation, which is based upon the principle of parties' self-determination is completely lost is such a process. As a result, the process echoes the adversarial traits.

Hence, the true nature of mediation undergoes drastic transformation if evaluation is permitted to be a part and parcel of it.

\subsection{Encroachment upon parties' right to self-determination}

The principle of parties' right to self-determination is paramount and constitutes the crux of mediation. ${ }^{21}$ Bush has very rightly observed that the central value echoed in the majority of literature on mediation is self-determination. ${ }^{22}$ Commonly accepted definitions of mediation as well as the regulatory standards embody this salient feature of mediation. ${ }^{23}$ This principle implies that it is the parties who are the decision-makers and not the neutral third-party. The mediator is required to enrich the information base and promote better

Kovach \& Love (n 14 above) 32.

Kovach \& Love (n 14 above) 32.

Love (n 4 above) 940 . Kovach \& Love (n 14 above) 31; 'mediator evaluation tends to perpetuate or create an adversarial climate. Parties try to persuade the neutral of their positions, using confrontational and argumentative approaches.'

19 A party is likely to exercise caution with the information he or she gives out during an evaluative mediation so that it does not adversely affect such evaluation and rather orients the mediator's decision in his/her favour.

Kovach \& Love (n 14 above) 32

Weckstein (n 3 above) 508.

RAB Bush 'Substituting mediation for arbitration: the growing market for evaluative mediation, and what it means for the ADR field' (2003) 3 Pepperdine Dispute Resolution Law Journal 111,115.

23 Annex-A CPFM (n 2 above) secs 5.1, 5.5. Annex-B CPCCM (n 2 above) secs 5.1, 5.5. 
understanding between the parties by encouraging them to reflect on the issues involved, reduce friction, explore their true underlying interests and find mutual points of accord to help them reach an agreement but not formulate any decision for them. ${ }^{24}$ 'In so doing, [mediator] [facilitates] evaluation by the parties. ${ }^{25}$ Party autonomy abets greater party participation, feeling of empowerment, satisfaction and greater compliance with the outcome.

Evaluation undermines party autonomy. Once the mediator takes on an evaluative role, parties lose control over the outcome. When a mediator ardently tries to evaluate the issue, the scope of negotiation between the parties ultimately narrows down as the parties begin to lose control ${ }^{26}$ and because the parties give importance to what the mediator says and rely on it, it may go on to shape their so-called 'independent' decision. ${ }^{27}$ It has been contended that, for the true realisation of self-determination, mediation must provide knowledge of law and the parties' legal rights. ${ }^{28}$ This knowledge may, however, hinder creative problem-solving by the parties and adversely affect the self-determination principle. There is a barrier erected by the evaluative mediator to the level to which parties are involved in the problem-solving processes and generating an array of alternatives for settlement. As a result, in an evaluative mediation not only does the level of parties' participation in the process fall, ${ }^{29}$ leaving the parties feeling dissatisfied, ${ }^{30}$ but there may also be lesser compliance with the outcome drawn up by the mediator. ${ }^{31}$ Accordingly, the parties may not perceive mediation to be a process any different from the adversarial processes.

24 KK Kovach \& LP Love 'Mapping mediation: the risks of Riskin's grid' (1998) 3 Harvard Negotiation Law Review 71,101; JD Feerick 'Toward uniform standards of conduct for mediators' (1997) 38 South Texas Law Review 455,458.

25 Love (n 4 above) 939

26 Kovach \& Love (n 24 above) 100

Alfini (n 4 above) 930 (quoting Donna Gebhart); C Menkel-Meadow 'Ethics in alternative dispute resolution: new issues, no answers from the adversary conception of lawyers' responsibilities' (1997) 38 South Texas Law Review 407,424; EA Waldman 'The evaluative-facilitative debate In mediation: applying the lens of therapeutic jurisprudence' (1999) 82 Marquette Law Review 155, 164; Levin ( $\mathrm{n} 1$ above) 271; C Menkel-Meadow 'Is mediation the practice of law' (1996) 14 Alternatives to the High Cost of Litigation 57, 61.

28 JM Nolan-Haley 'Court mediation and the search for justice through law' (1996) 74 Washington University Law Quarterly 47, 49-52, 91.

29 Kovach \& Love (n 24 above) 99, 100. EA Lind et al 'Voice, control, and procedural justice: instrumental and non-instrumental concerns in fairness judgments' (1990) 59 Journal of Personality \& Social Psychology 952, 953: '[P] eople actively reject procedures that appear to offer process control but that do not provide any real input into the decision-making process'; Riskin (n 4 above) 45. Alfini (n 4 above) 930 (quoting Gebhart) Riskin (n 4 above) 45.

EC Directive (n 2 above) art 3(a), Preamble para (6); It recognises mediation as a process wherein 'parties to a dispute attempt by themselves, on a voluntary basis, to reach an agreement on the settlement of the dispute' and expressly notes in its Preamble para (6) that 'agreements resulting from mediation are more likely to be complied with voluntarily and are more likely to preserve an amicable and sustainable relationship between the parties'. 


\subsection{Impugned neutrality and impartiality}

In conjunction with principle of self-determination, the mediator's neutrality and impartiality are fundamental principles of mediation. ${ }^{32}$ The mediator must not only be neutral and act in a fair and evenhanded manner throughout the process, ${ }^{33}$ but must also be perceived by the parties as such. ${ }^{34}$ Mediation must be conducted in an impartial way and the mediator must not try to impose any preferred outcome on the parties, ${ }^{35}$ 'whether by attempting to predict the outcome of court or formal proceedings or otherwise'. ${ }^{36}$ The mediator must not give advice to the parties, individually or collectively. ${ }^{37}$ If such conduct is not maintained, it may impair not only the mediator's position but also parties' right to self-determination. Riskin has observed that the higher the degree of evaluation, the greater is the need for impartiality. ${ }^{38}$ Likewise the lower the degree of intervention by the mediator the lesser the challenge posed to the mediator's position.

Roberts \& Palmer ${ }^{39}$ in their summarisation of Simmel $^{40}$ on the idea of a non-aligned third-party intermediary observed that 'a defining characteristic of the mediator is that he or she is not a partisan'. An activistic mediator is likely to be a partisan as evaluation invariably ends up favouring one party at the expense of the other. ${ }^{41}$ When any opinion is given on the merits of the case, or any part of a statute is put forth or the attention of the parties is brought to a particular article chosen by the mediator, it can never be said to be completely objective. ${ }^{42}$ This is so because the mediator may have certain notions of either the outcome in court proceedings 'in the shadow of the law, 43 or some predisposed stance towards the party. Such behaviour,

Annex-A CPFM (n 2 above) sec 3.1; Annex-B CPCCM (n 2 above) sec 3.1; CMCPM (n 2 above) para 4.2,4.3; European Code of Conduct for Mediators para 2.2 http:// www.ec.europa.eu/civiljustice/adr/adr_ec_code_conduct_en.pdf (accessed on 14 November 2011) (ereinafter 'ECCM'); EC Directive (n 2 above) arts 4(2),3(b); the definition of a mediator provided by the EC Directive also reiterates it. Annex-A CPFM (n 2 above) sec 3.2.3; Annex-B CPCCM (n 2 above) sec 3.2.2; CMCPM (n 2 above) para 4.3.1.

ECCM (n 32 above) para 2.2; Levin (n 1 above) 294; Riskin (n 4 above) 47. Annex-A CPFM (n 2 above) sec 5.5; Annex-B CPCCM (n 2 above) sec 5.5.

CMCPM (n 2 above) para 4.2, 6.9.

Annex-A CPFM (n 2 above) Introduction; Annex-B CPCCM (n 2 above) Introduction. Riskin (n 4 above) 47.

Roberts \& Palmer (n 11 above) 154.

G Simmel The sociology of Georg Simmel (1950) 149-150.

Kovach \& Love (n 14 above) 31.

Alfini (n 4 above) 927, 928, quoting McDonald; Stark (n 4 above) 785, discussing how student mediators would make a choice as regards the information they would provide as mediators; Levin (n 1 above) 294; Menkel-Meadow (n 27 above) 61.

43 RH Mnookin \& $L$ Kornhauser 'Bargaining in the shadow of the law: the case of divorce' (1989) 88 The Yale Law Journal 950. 
in addition to distorting the mediator's image as a neutral and impartial figure, may also cause the parties to flee from mediation. ${ }^{44}$

\subsection{Competency of mediators questioned}

Mediation (in England) is open to all. The league of mediators comprises people of 'different rank and ambition'. ${ }^{45}$ This openmarket approach is put to risk if the evaluative-mediator approach is promoted and adopted. When mediators evaluate a case applying the relevant law to the specific facts, they engage in the practice of law. ${ }^{46}$ These activities require a high degree of professional competence ${ }^{47}$ and are put in the spotlight particularly when the mediator-pool consists of people varied in knowledge and skills. In a situation where, for instance, a non-expert mediator (for example a neighbour) evaluates, the mediator may not be well versed with the legal position on the subject-matter. In such a scenario, it inevitably implies that the mediator must be one who is well versed with legal principles or even better, a practitioner of law. Mediators may not be qualified to serve as case evaluators or even if they are, they may not be able to carry out their task bearing in mind their neutral and impartial position in the process. Thus, in a case where there may be an imbalance of power between the parties and there is a lawyermediator, restriction is nevertheless placed on the mediator on the grounds of his/her neutrality and impartiality.

The facilitative approach deals well with the above set of conditions. With this approach in hand, a mediator need not be an expert. If there arises any situation where the mediator is faced with legal questions such as informed decision-making by the parties or dealing with power-imbalances, he/she may direct the parties to seek independent legal or other professional advice. ${ }^{48}$ This also ensures congruence with principle of self-determination and the neutral and impartial position of the mediator.

Evaluative mediation also tends to diminish the quality of mediation. Given that the mediator can be almost anyone and that mediators do not receive decision-making training, the prediction of case outcomes by such mediators is debatable. ${ }^{49}$ The parties may look up to the mediator as a person with expertise in the subject-area but

Love (n 4 above) 938. If a party believes that the mediator has sided with the other party, it may retreat from the process.

45 Roberts \& Palmer (n 11 above) 153.

46

Menkel-Meadow (n 27 above) 424; Menkel-Meadow (n 27 above) 61 Riskin (n 4 above) 46: Riskin notes that increase in the need for subject-matter expertise is directly proportional to the parties' need for the mediator's evaluations.

47 Alfini (n 4 above) 933, quoting Love.

48 Alfini (n 4 above) 933, 934, quoting Love; CMCPM (n 2 above) paras 6.10,6.17;

49 Annex-A CPFM (n 2 above) sec 5.10, 5.11; Annex-B CPCCM (n 2 above) sec 5.4,6.3.

49 Kovach \& Love (n 24 above) 104; Kovach \& Love (n 14 above) 31. 
in reality, he/she may not have information any more than the parties and may be in a poor position to render an evaluation. ${ }^{50}$

\subsection{Clogging market-growth}

If it is acceptable for mediators to render opinions on the merits of the case or predict the likely outcome of a court's decision, then only lawyers and other expert (such as retired judges) will be fit to be mediators. ${ }^{51}$ Mediation, as noted above, is open to all. This helps in the formation of a rich heterogeneous mediator-pool with talents, calibers, and perspectives of people based in different disciplines. ${ }^{5} \dot{3}$ Mediation in its pure form does not involve law but communication along with other skills. ${ }^{53}$ These include human relations, interpersonal dynamics, communication skills, negotiation and bargaining skills, gender and generational dynamics, organisational and managerial skills and a rich information base regarding particular industry or disputes among others. ${ }^{54}$ No single category of professionals fits the bill with respect to each of these requirements. ${ }^{55}$ At times, parties may not even desire lawyers or experts to act as mediators. They may have the apprehension that such persons are pre-disposed with respect to the subject matter on account of their experience in the field. ${ }^{56}$

If limitations are placed on the entry into the market, there would be a substantial loss in the mediator-pool resource which would in turn obstruct creative problem-solving by the parties and full realisation of their right to self-determination. ${ }^{57}$ Mediation must not be '[legalised]' and made the private domain of lawyers. ${ }^{58}$ If this is allowed it may end up in an unhappy two-faceted result for mediation. Firstly, it may drain out the mediator-pool resources, as noted above. Secondly, as lawyers would never shed their evaluative habits, mediation would be pulled back into the adversarial framework. ${ }^{59}$

Levin (n 1 above) 287

Love (n 4 above) 941.

Love (n 4 above) 942; Love (n 9 above) 741.

Menkel-Meadow (n 27 above) 61.

Love (n 9 above) 741 .

Love (n 9 above) 741; Feerick (n 27 above) 468

Feerick (n 24 above) 467.

Love (n 4 above) 942.

Schuwerk (n 4 above) 761

Kovach \& Love (n 14 above) 32; Kovach \& Love (n 24 above) 105; Love (n 4 above) 942. 


\subsection{Parties left without any remedy}

Mediators have a duty to conduct mediation in a confidential way. ${ }^{60}$ This means that the sessions are conducted in a private and legally privileged manner subject to certain exceptions provided in the regulatory standards. ${ }^{61}$ Unlike litigation and arbitration where there are provisions for the parties to appeal against the decision of the evaluator, there is little or virtually no safeguard against a mediator's inadequately informed opinion. ${ }^{62}$ Confidentiality shields the careless and erroneous mediator's opinions from public scrutiny and results in a failure of professional accountability on the part of the mediators. ${ }^{63}$ The confidentiality aspect here seeks to protect the mediator from any accountability but on the other hand, damages the parties' position who may end up feeling even worse than before they started mediating. Also, evaluation by the neutral third-party:

based in some part on information obtained in caucuses (without the opportunity for rebuttal by other side) rests on inferior evidence than the evidence that an arbitrator, judge or jury would have. ${ }^{64}$

For instance where a mediator is a layman with respect to the subject matter involved, an evaluation made by him/her based on incomplete or limited information, on substandard evidence or in the absence of specialist opinions can be highly speculative. ${ }^{65}$ As noted above, the parties may inevitably rely on the mediator's opinion. In such circumstances, it means that the parties have virtually no remedy against the mediator when they bank on the information by the mediator that may be unjust, unfair or plain wrong. ${ }^{66}$ The problem is essentially two fold - firstly, if there is no remedy against the incorrect evaluation, it would leave the parties without any form of redressal against the action of the mediator and secondly, if there is a remedy provided to the parties' to institute proceedings against the mediator, it would pull mediation back in the adversarial framework. paras 4.5, 4.6; Annex-A CPFM (n 2 above) sec 7; Annex-B CPCCM (n 2 above) sec 7.

61 EC Directive (n 2 above) art 7; ECCM (n 32 above) para 4; CMCPM (n 2 above) para 4.6; Annex-B CPCCM (n 2 above) sec 7; Annex-A CPFM (n 2 above) sec 7.

62 Love (n 4 above) 942.

63 Kovach \& Love (n 24 above) 104

64 LP Love \& JW Cooley 'The intersection of evaluation by mediators and informed consent: Warning the unwary' (2006) 21 Ohio State Journal on Dispute Resolution 45, 58; Kovach \& Love (n 14 above) 31 (They noted that the conventional decision makers operate within a framework of ethical norms and legal standards which direct their evaluation. This is however not the case with mediators.).

65 Love \& Cooley (n 65 above) 58; Riskin (n 4 above) 111 - he notes that the facilitative mediator may not know enough about the relevant law, practices or technology to render an informed opinion.

66 Menkel-Meadow (n 27 above) 61. 


\section{Conclusion}

Mediator activism is wholly inconsistent with the core founding principles of mediation. The regulatory standards neither expressly endorse evaluation nor do they expressly bar it. However, a degree of refinement and uniformity in the definition of mediation is required. This is crucial for the growth and development of mediation. ${ }^{67}$ The public should understand the essential nature of each dispute resolution process $^{68}$ and be able to distinguish it from others. ${ }^{69}$ Uniform understanding of mediation would help prevent the weakening of mediation's unique advantages. ${ }^{70}$ Lessons must be learnt from the growth of arbitration which originated as a true 'alternative' to litigation but eventually ended up getting aligned with the adversarial processes. ${ }^{71}$ Over a span of time, it lost its many attributes that made it appealing initially. ${ }^{72}$ Similarly, if evaluation in mediation is permitted, it can have parallel adverse implications. To ensure high quality of mediation and minimal unfairness or mistake, the best and safest practice with respect to both - the parties as well as the mediators - is that the process be left in its original facilitative form. Therefore, it may be concluded that mediation must be conserved in its pristine form so that it does not fall into the pit falls of adversarial system.

Love (n 4 above) 946.

Kovach \& Love (n 14 above) 32

Love (n 4 above) 948 (stating that processes different from mediation must be 'labeled' as such and not be mixed with the understanding of mediation in any way).

Kovach \& Love (n 24 above) 87.

Kovach \& Love (n 24 above) 90.

As above. 